
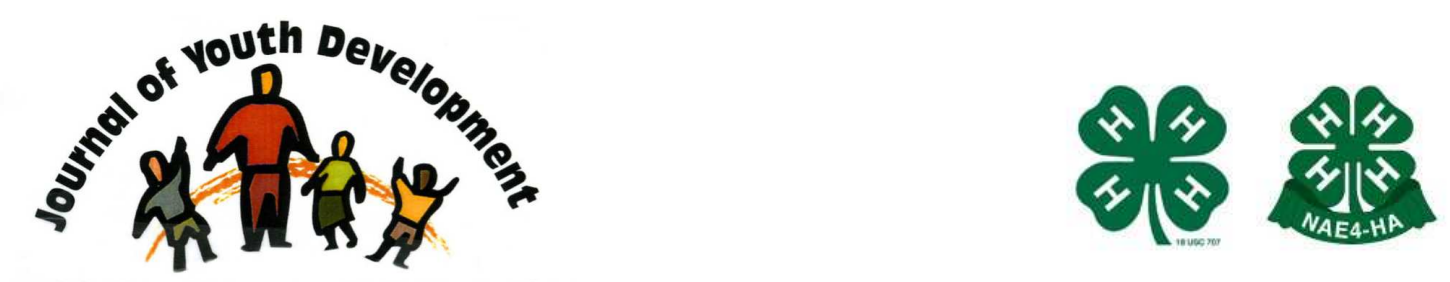

Bridging Research \& Practice

\title{
Model Youth Programs: A Key Strategy for Developing Community- University Partnerships Using a Community Youth Development Approach
}

\author{
Yolanda Anyon \\ School of Social Welfare \\ Berkeley, CA \\ yanyon@stanford.edu \\ María A. Fernández \\ John W. Gardner Center for Youth and Their Communities \\ Stanford, CA \\ mafernandez@stanford.edu
}




\title{
JOURNAL OF YOUTH DEVELOPMENT \\ bridging research and practice

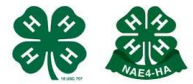

Volume 3, Number 1, Summer 2008

Article 080301PA002

\section{Model Youth Programs: \\ A Key Strategy for Developing Community-University Partnerships Using a Community Youth Development Approach}

\author{
Yolanda Anyon and María Fernández \\ Stanford University
}

Abstract: Universities across the nation face the charge of enhancing their intellectual capital as a learning institution while also contributing to the greater social good. While there is great potential for universitycommunity partnerships to generate lessons for youth workers and policy makers, create powerful new knowledge for the academic field, and provide transformative experiences for community members, partnerships often fail to produce such meaningful results. In the San Francisco Bay Area, community residents who have been involved in such unsuccessful initiatives frequently perceived that university partners spent insufficient time learning about the community context, prioritized research objectives over community needs and did not make long-term commitments. Despite these challenges, communityuniversity partnerships can be useful strategies for advancing the field of youth development by strengthening research and practice in local contexts.

This paper presents how the design and implementation of model youth programs served as an effective strategy in developing a partnership between a university-based center and two local communities over a 5year period. It also describes essential lessons that other communities, research institutions or universities may use to launch, implement, expand and sustain their own successful partnerships to build local capacity to implement youth development practices, promote positive outcomes for young people, and generate knowledge about the impact of youth development approaches. 


\section{Introduction}

In the fall of 2000, the John W. Gardner Center for Youth and Their Communities (JGC) initiated partnerships with two San Francisco Bay Area communities to generate better outcomes for young people and develop new knowledge and resources for research and practice in youth development. Guided by a community youth development philosophy, the JGC was able to overcome many of the challenges that have historically plagued community-university partnerships.

The community youth development approach values the voices of young people and residents, focuses on assets, and emphasizes collaboration (Hughes \& Curnan, 2000; Pittman, 1996). A key strategy within this process was to co-develop and implement a model youth program in each community. This effort created the necessary conditions for a strong partnership that would develop new knowledge and resources for research and practice in youth development (Harkavy, 2006; Jacoby, 2003). This paper will outline the approach the JGC used and highlight essential lessons learned about partnership development as the youth program unfolded.

\section{The Historical Context of Community-University Relations}

Universities across the nation face the charge of enhancing their intellectual capital as a learning institution while also contributing to the greater social good (Burkhardt, J., Chambers, T., \& Kezar, A., 2005). Efforts to fulfill the latter come in many forms: college students volunteering in community programs; faculty conducting research activities to support local reform efforts; or university centers and civic leaders launching major community development initiatives (Erlich, 2000). In some cases, collaborative endeavors result in powerful new knowledge for the academic field and transformative experiences for community members. Other partnerships fail to produce such meaningful results. In the early stages of developing the JGC, staff members asked Bay Area community members to share their experiences in such unsuccessful initiatives. These residents perceived that university partners:

- Spent insufficient time learning about the community context: researchers had theories about how to fix neighborhoods, but they did not consider the experiences and ideas of residents. Researchers focused on obvious community deficits and problems without exploring strengths and assets.

- Prioritized research objectives over community needs: information from community-based research projects was not translated into accessible formats or practical tools that community members could utilize to solve local problems. Instead, the data were primarily used to address an academic audience, with few direct benefits to those who were being researched.

- Did not commit to long-term goals or strategies: faculty members initiated projects that were connected to short-term grants. Once the funding cycle came to a close, so did the partnership.

Historically, mistrust has been particularly strong in communities of color that have been exploited in medical research experiments or pathologized by scholars. The concerns of our partner communities reflect such experiences. These perceptions, actual or imagined, are oftentimes compounded by the real differences that exist between academic institutions and under-resourced communities in terms of privilege, power, and values. 


\section{A Community Youth Development Approach to Partnerships}

The JGC was established to strengthen policy, practice and research in the field of community youth development (CYD). This particular focus on community-university partnerships is driven by the vision of John W. Gardner, a nationally renowned civic leader and public servant. Throughout his lifetime, Gardner often spoke of the indispensable role of the university as a member of the broader community with responsibility to improve the quality of life for everyone. He believed that universities could make unique contributions to local efforts that aim to improve the well-being of young people (Gardner, 1968). Gardner also recognized that residents had distinct knowledge that could inform and build the academic field of community youth development (Gardner, 1965).

Community youth development is an approach predicated on the belief that the health of young people and their communities are interdependent. As Hughes and Curnan (2000) describe, CYD strategies "harnesses the power of youth to affect community development and, similarly, engages communities to embrace their role in the development of youth" (p. 1). Youth and their communities are not problems to be fixed; they are essential partners with assets and expertise (Pittman, Irby, Tolman, Yohalem, \& Ferber, 2003). This framework also acknowledges that young people grow up in communities, not isolated programs or systems; they develop physically, intellectually, psychologically and socially all at once. Therefore, programs and systems intended to support them should be well-coordinated and context-driven in order to maximize effectiveness. Furthermore, a CYD approach recognizes that the task of creating meaningful and lasting change requires a long-term investment and commitments from all stakeholders (Eccles, 2002).

The JGC's approach to partnerships applied the main principles of CYD in response to challenges that have often hindered other collaborative efforts for youth in the past. In order to develop a common vision with partners, the JGC first learned about a community's history and context through open-ended conversations with residents and local leaders. The JGC made a particular effort to include all critical stakeholders, including young people and institutional leaders, in early planning efforts. The discussions also identified potential goals and objectives. JGC staff members then worked with local partners to co-construct model programs that built on effective research-based youth development practices as well as community knowledge. These shared efforts led to new relationships between the university and community, which were leveraged to create opportunities for research and action that aim to have a lasting impact on young people's lives.

\section{The Strategy of Implementing Model Programs}

The steps and lessons presented here are derived from case studies of partnerships between the JGC and two local communities: Redwood City and West Oakland. Although the partnerships in each community have evolved in different ways, they both began with a youth leadership program, Youth Engaged in Leadership and Learning (YELL). For the past six years, YELL has provided Kennedy Middle School and McClymonds High School students with the opportunity to lead action projects on social justice issues they find important and relevant.

Throughout the program, youth learn research, advocacy and organizing methods in order to seek and implement answers to the difficult problems that face their school and community. YELL participants use these skills and knowledge to inform and improve local youth and education policy through shared decision-making with adults. Beginning with 2 cohorts of 
approximately a dozen young people at the program's inception, the project now supports almost 200 youth.

The process of co-developing and implementing YELL within each community was a key strategy to create the necessary conditions for successful collaboration on systems-level research and action efforts. As a JGC- sponsored program, YELL fundamentally changed the dynamics between the community and the university. Community partners no longer perceived the university to be an elite institution, but instead associated it with a set of human relationships built on mutual respect and trust. Furthermore, seeing the YELL model in action prompted a range of stakeholders to become more deeply invested in CYD strategies and more willing to engage in a partnership with the JGC to better support youth in their communities.

With respect to building a partnership, the JGC had three main objectives in co-creating and sponsoring YELL as a model program within a CYD framework. This paper will highlight examples and lessons learned in meeting each of these objectives.

- Objective 1: Address Negative Perceptions of University Partners

- Objective 2: Generate Community Commitment to a CYD Approach

- Objective 3: Engage in Systems-Level Change

\section{OBJECTIVE 1: Address Negative Perceptions of University Partners}

To change community members' negative perception of the university, the JGC had to:

- Understand the community context and co-construct the model program with partners

- Support both research and practice

- Develop agreements for sustainability

Understand Community Context and Co-Construct the Model Program with Partners Instead of the university setting the agenda with preconceived ideas about the nature of the partnership or model program, the JGC's first role was to listen to community leaders and learn about the local context before making any decisions. JGC staff members spoke with city leaders, school staff and members of community-based organizations in both Redwood City and West Oakland about their past experiences and new ideas for better supporting young people.

All voiced a need for more coordinated systems, services, and supports for young people in and out of school. In these conversations, community members also expressed a need for more information and additional research before setting the partnerships' agendas. In particular, community leaders wanted to better understand how academic theories of youth development could be adapted to inform local programming that was appropriate for their neighborhood context. Policy makers, funders and practitioners also wanted to assess the everyday experiences and needs of local youth and their opinions about how to improve existing services. It quickly became clear that both communities would benefit from developing youth leaders who could generate new knowledge about youth to inform local decision making. Out of these discussions emerged a program design for YELL in which young people led action research projects on issues important to youth.

Essential Lesson: Frame initial conversations broadly. The JGC did not come prepared with proposals or solutions to these early meetings. Community leaders were surprised to hear that the Center did not have a specific program or particular grant in mind. Instead, the guiding question for partnership development was, "What might we be able to do together to further 
support young people?" This framing proved to be effective in opening rather than closing doors.

\section{Support Both Research and Practice}

To overcome perceptions of the university as only acting in academic self interest, the JGC's second task was to ensure YELL supported the JGC's research and dissemination goals along with the community's need for high quality training and direct service. Therefore, it was critical that YELL's design was informed by effective practices that could be aligned with concrete research questions about their effectiveness within a particular community context. That way, the knowledge gained from this work could be shared with the academia, but would also allow the JGC to create tools, models and strategies that local community members could also use in their practice.

Essential Lesson: Give program coordinators explicit responsibilities in both research and practice. In order to eliminate any impression that one set of goals was more valuable than the other, Center staff worked diligently to make the work of running the program and documenting the youths' experience as seamless as possible. In particular, the YELL Director served a critical role of research-practitioner with two primary responsibilities: interface with the youth and community members to meet program goals and also support university students and staff in implementing the research agenda. As a result, the documentation of youths' experiences in YELL was an intentional effort to bridge research and practice. These multipurpose data were used to answer academic questions, contribute to program improvement, support grant evaluations, advocate for additional funds, and share successful program strategies through curricula and training.

\section{Develop Agreements for Sustainability}

Many community-university partnerships face challenges in securing and sustaining the financial resources needed to support their work. However, as a new center with support from Stanford, the JGC was in a unique position to support YELL's early development. Housed within a school of education at a major research university, the JGC had expertise to offer in research training, curriculum development, data collection and analysis. Furthermore, the JGC had been awarded initial research and development funds from a foundation for a feasibility study of partnerships in local communities. Community partners offered in-kind resources such as staff time, local knowledge, connections, space, equipment, and commitment to making the program work.

The JGC assumed managing responsibility for the YELL program with verbal agreements and trust that both parties were committed to a long-term partnership. But as the JGC began longterm strategic planning, executive leadership questioned the organization's ongoing responsibility for managing YELL after five years of implementation, particularly since more than enough data had been collected to meet research goals. Some believed that partners should offer more ownership and responsibility for the program given the benefits it provided for local youth. However, the JGC had also benefited significantly through this collaboration and these communities already struggled with scarce financial resources. At this point, questions of what each partner would ultimately and officially be accountable for had to be addressed. These conversations were difficult and brought out old suspicions that the university would back out. Once these fears were assuaged, community partners assumed primary responsibility for managing the program, with technical assistance from the JGC, including short-term fundraising support as community partners worked to take more of a lead in leveraging resources. 
Essential Lesson: Create a plan for sustainability and shared accountability up front. Although a two or three-year grant was enough to launch a youth program, it did not represent the kind of long-term investment needed to see meaningful community change. Communities want to see that universities are partners for the long haul, not just when the grant money is available. This kind of enduring partnership requires foresight, planning and difficult conversations about shared responsibilities from the start of model program development. In the case of YELL, confusion could have been avoided by creating a Memorandum of Understanding for the partnership and each program as it developed during the first year of implementation. An MOU that outlined each party's specific responsibilities, including fundraising roles, would have provided a concrete framework for conversations as the partnership evolved and changed.

\section{OBJECTIVE 2: \\ Generate Community Commitment to a CYD Approach}

A second major goal of the JGC's model program strategy was to generate community investment in a CYD approach. In particular, community members wanted to see how related academic theories were relevant and useful in local improvement or reform efforts. In order to meet this need, the JGC used YELL to:

- Model effective practices in community youth development

- Develop positive relationships with community leaders and stakeholders

\section{Model Effective Practices in Community Youth Development}

YELL was developed in part to create a model that demonstrated the effectiveness of a community youth development approach, with a particular focus on youth voice in decision making. Through YELL, the JGC adapted effective practices to local contexts before suggesting that schools or community-based organizations embed these strategies in their own work. YELL served as a tool to translate CYD theories into concrete examples from which partners could draw lessons and inspiration. As partners observed their own youth successfully fulfilling roles as researchers and advocates, they became more excited about the potential of youth leadership and more willing to develop new venues for youth voice and involvement.

In addition to informal observations by community members, researchers affiliated with the project gathered evidence from YELL that CYD strategies actually worked. Student participants completed pre- and post- surveys and interviews that measured their growth in positive youth development outcomes. Not only did YELL have a measurable impact on the lives of participating youth, the program also led to more supports and opportunities for young people in their schools and larger community (The impact of the YELL program has been documented elsewhere. For example, see: Kirshner, B. Strobel, K., Fernández, M.A., 2003; Strobel, K., et al., 2006).

Partner schools now offer the YELL program as a course during the mainstream school day, have created structures for youth voice in decisions about school policy and youth programming, and use YELL curriculum to enrich classroom and after school learning. For example, in Redwood City, YELL students sit on school decision-making bodies and are participating in civic activities in greater numbers. In West Oakland, youth were part of a major school reform effort that created small schools within the larger school site, while others serve as key decision makers and evaluators in the high school's after-school initiative. The Oakland Unified School District now collects data on youths' perspectives, modeled after YELL research, at all grade levels. In this way, YELL became an important vehicle for the JGC to introduce 
innovative approaches and ideas that could encourage other stakeholders in the community to embrace youth voice.

Essential Lesson: Translate academic theories into applied strategies. While the JGC rarely found partners who disagreed with theories of community youth development, community members often expressed skepticism about how CYD strategies could successfully be applied in their neighborhoods, with their youth. Model programs that translate theory to local practice proved to be effective tools for generating the will of school and community leaders to move from theory to action and implement strategies on their own.

\section{Develop Positive Relationships with Community Leaders and Stakeholders}

In early conversations, community leaders shared that past relationships with university researchers were often distant and detached. The JGC understood that strong relationships were the building blocks to a comprehensive partnership that could improve outcomes for youth. Through YELL, the JGC worked side by side with partners and essentially became embedded researchers. Staff members gained credibility by working directly with youth and demonstrating commitment by doing rather than just telling. As a result, the JGC had the unique opportunity to learn about the day-to-day challenges faced by youth and the adults who serve them. Furthermore, with time and trust, community members began to open doors to research and program staff that were previously closed to outsiders. As a result, the JGC had unprecedented access to local leaders and informal settings where decisions about policy, practice and research are made.

Essential Lesson: Invest significant time and resources early on to building relationships. Developing positive relationships with youth and respected school or community leaders created a ripple effect to counter negative perceptions of the university with other members of the community. These crucial players served as champions for the partnership, brokering additional relationships and setting the stage for partnership efforts to expand.

\section{OBJECTIVE 3: Engage in Systems-Level Change}

While the development and implementation of model programs reaps immediate rewards for youth participants and local communities, the ultimate goal of these partnerships is to create long-lasting systemic change. To position the JGC for involvement with partners in systemslevel work, staff members leveraged relationships built through YELL to:

- $\quad$ Expand youth development opportunities in the community

- Develop new research projects that could inform policy

\section{Expand Youth Development Opportunities in the Community}

YELL staff, products, events and images promoted positive public perceptions of the JGC and led to greater willingness to engage in collaborative efforts. Relationships built during the programs' implementation were leveraged to expand CYD programming for more youth in the community. In West Oakland, YELL participants used research data to obtain funding for a youth and family center. Today, that effort has grown to include youth leading evaluations and grant-making processes for the programs at the center. In Redwood City, local YELL data was used to secure funding for a family resource center which now serves hundreds of students every year. 
Relationships built from YELL also provided the JGC with access to information about emerging prospects for systemic reform. For example, connections from YELL at Kennedy Middle School in Redwood City led to the participation of multiple schools in a reform effort to develop community schools that bring together schools, families and the broader community to better support youth. Today, that work has deepened with two of those middle schools to address issues faced by schools and youth during this critical age. Similarly, because of the relationships staff members had with school leaders through YELL, in West Oakland the JGC was able to work with school leaders on an effort to integrate and align in-school and out-ofschool learning through professional development and collaborative projects between teachers and youth workers.

Essential Lesson: Maximize relationships to engage in systemic reform. The JGC leveraged relationships from YELL to expand community youth development programming and engage in broader reform efforts. The credibility and connections from model program implementation served as critical tools for engaging partners in systems-level change efforts.

\section{Develop New Research Opportunities That Can Inform Policy}

The JGC also capitalized on relationships in the community to initiate research projects that would answer both academic and practical questions. These research projects provided faculty members, along with graduate and undergraduate students, unique access to research subjects within their community contexts.

For example, Stanford faculty and students had the opportunity to study the process in which West Oakland students become disconnected from the institutions meant to serve them and become significant costs to the state. McClymonds High School granted researchers permission to shadow cohorts of high school students throughout the school day and into the neighborhood. In Redwood City, city and county officials are working with the JGC to look at youth data across systems to examine how young people move between various institutions such as health, welfare, education and other community or school-bases services. Both projects intend to identify ways to reengage young people and understand what can be done to better support them. However, given the history of academic institutions in these communities, these research activities are extraordinary and reveal the power of relationships built through model programs.

\section{Essential Lesson: Site-based placement of university staff can yield critical knowledge for} researchers and practitioners. Since JGC staff members were embedded in the community, they were privy to local knowledge that could be used to develop research questions to inform policy. Lessons learned from these real-life CYD settings came back to the university to inform theory and support the development of future leaders across academic disciplines. Staff members' dual roles as research-practitioners also supported this goal. Instead of sending university "experts" out to the field to train community leaders and providers with what "the research says" about supports young people need, the JGC partnered with these individuals to bring the expertise of both the university and community members to build better tools, resources, and local models of community capacity together. YELL program directors served as "critical friends" to partners and shared YELL research results to local leaders in a way that depoliticized and did not feel like an attack from an outsider. In other words, community members believed in the JGC's good intentions and understood that the Center's research was intended to support improvement efforts, not to punish. Community responses to researchers recommendations were purely voluntary and there was no mandate or consequence attached to 
study results - only the shared vision for promoting an approach that support the positive development of the community's youth.

\section{Conclusion}

Universities will continue to face challenges presented by the checkered history of universitycommunity partnerships. However, a community youth development approach, with model youth programming as a key strategy, can help realize the promise of community-university partnerships.

\section{References}

Eccles, J., \& Appleton, J.A. (Ed.). (2002). Community programs to promote youth development. Washington, DC: National Academy Press.

Erlich, T. (Ed.). (2000). Civic responsibility and higher education. Phoenix, AZ: Oryx Press.

Gardner, J.W. (1965). Self-renewal: The individual and the innovative society. New York: Harper \& Row.

Gardner, J.W. (1968). No easy victories. New York: Harper \& Row.

Harkavy, I. (2006). The role of universities in advancing citizenship and social justice in the 21st century. Education, Citizenship and Social Justice, 1(1), 5-37.

Hughes, D.M., \& Curnan, S.P. (2000). Community youth development: A framework for action. CYD Journal, 1(1), 7-11.

Burkhardt, J., Chambers, T., \& Kezar, A. (Eds.). (2005). Higher education for the public good: Emerging voices from a national movement. San Francisco, CA: Jossey-Bass.

Jacoby, B. (Ed.). (2003). Building partnerships for service-learning. San Francisco, CA: JosseyBass.

Kirshner, B., Strobel K., Fernández, M.A. (2003). Critical civic engagement among urban youth. Critical civic engagement among urban youth, 2(1).

Pittman, K. (1996). Community, youth, development: Three goals in search of connection. New Designs for Youth Development, Winter.

Pittman, K., Irby, M., Tolman, J., Yohalem, N., \& Ferber, T. (2003). Preventing problems or promoting development: Competing priorities or inseparable goals? Washington, D.C.: Forum for Youth Investment. 
Strobel, K., Osberg, J., and McLaughlin, M. (2006). Participation in social change: Shifting adolescents' developmental pathways. In S. Gingwright, Noguera, P., and Cammarota, J. (Ed.), Beyond Resistance: Youth Activism and Community Change: New Democratic Possibilities for Policy and Practice for America's Youth. Oxford, UK: Routledge.

** A different version of this project, directed to leaders and administrators in higher education was published in the November/December 2007 issue of Change Magazine, Heldref Publications. The article, "Realizing the Potential of Community-University Partnerships." Is authored by Yolanda Anyon and Maria A. Fernández.

(C) Copyright of Journal of Youth Development Bridging Research and Practice. Content may not be copied or emailed to multiple sites or posted to a listserv without copyright holder's express written permission. However, users may print, download or email articles for individual use. 